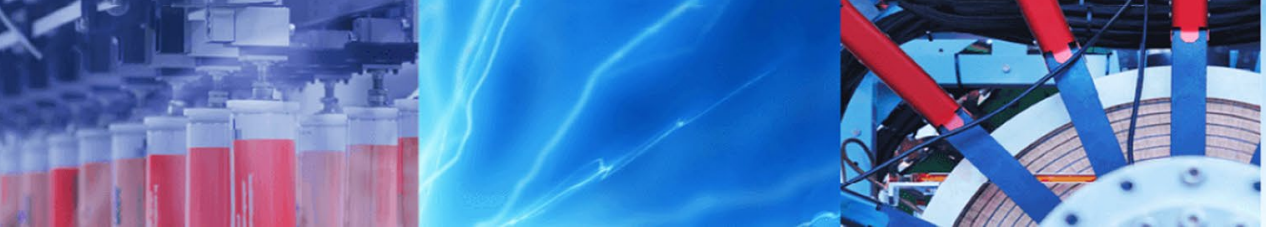

Research Article

\title{
Analytical solution for free vibration of stiffened functionally graded cylindrical shell structure resting on elastic foundation
}

\author{
Van-Loi Nguyen $^{1}$ (D) Thu-Phuong Hoang ${ }^{1}$
}

○) Springer Nature Switzerland AG 2019

\begin{abstract}
In this work, the analytical solution for free vibration of functionally graded cylindrical shell with stiffeners resting on Winkler-Pasternak foundation with several boundary conditions is reported. Material properties of the cylindrical shell are assumed to be varying smoothly and continuously across the thickness according to the power law distribution of the volume fraction of constituents. The governing equations of the stiffened functionally graded cylindrical shell resting on elastic foundation are obtained by using Hamilton's principle, the first-order shear deformation theory and the Lekhnitsky smeared stiffeners technique. The purpose of the present study is to illustrate a simple approach to get the natural frequency of the stiffened functionally graded cylindrical shell with several boundary conditions by using the Galerkin method with beam functions of the axial displacement fields. A good agreement is obtained as the present results in comparison with those of publications in the existing literature. In numerical investigations, some influences of volume fraction index, cylindrical shell's geometric ratios, boundary conditions and elastic foundation parameters on the fundamental frequency of the stiffened cylindrical shell resting on elastic foundation are given.
\end{abstract}

Keywords Free vibration - Stiffened functionally graded circular cylindrical shells - The first-order shear deformation theory · Different boundary conditions - Winkler-Pasternak foundation

\section{Introduction}

Shell and plate structures have a wide range of applications in engineering fields such as civil engineering, aircraft engineering, shipbuilding industry, and nuclear reactor, etc. Static and dynamic behaviors on these kinds of structures usually have gotten much more attentions by scientists throughout the world. In particular, there are rather many studies in the existing literature on behaviors of continuous systems such as beams, plates, and shells [1-10]. For isotropic and laminated composite materials, studies on free vibration of un-stiffened and stiffened cylindrical shell can be found in publications [11-26].

In the next stage, together with advanced technology, a kind of new material is proposed called functionally graded material (FGM). This material has two constituent materials - ceramic and metal, and its material properties are assumed to be varying continuously and smoothly throughout the thickness of the structure. Thanks to this, the structures have many advantages of both ceramic and metal constituents such as high strength, toughness, and good capacity of corrosion and thermal resistance, etc. Interestingly, static and dynamic behaviors of the FGM structures have been still attracted many the scientists in the past years. In terms of the plate and shell theories, several models have been introduced. For instance, the classical plate theory, this theory was proposed first, based on the Kirchhoff's assumptions and ignoring the transverse shear deformation effects, hence this theory is only appropriate for the thin plate $[27,28]$. To overcome that limitation, there are some models of the shear deformation theories are given such as the first-order shear

\footnotetext{
$\triangle$ Van-Loi Nguyen, nguyenvanloi.n.v@gmail.com; loinv@nuce.edu.vn | ${ }^{1}$ Department of Strength of Materials, National University of Civil Engineering, 55 Giai Phong Road, Hai Ba Trung District, Hanoi, Vietnam.
} 
deformation theory (FSDT) $[29,30]$, the higher-order shear deformation theories [31-33], and the simple first-order shear deformation theory [34-37]. In terms of the stiffened shell structures, studies about stiffened cylindrical shell were presented in many publications [38-41]. Many scientists also reported some researches on free vibration of functionally graded cylindrical shell resting on and not resting on elastic foundation are reinforced by rings or orthogonal stiffeners in the recent years [42-49].

On the other hand, modern numerical methods such as the finite element method (FEM) have been widely used in static and dynamic behaviors of the plate and shell structures [50-53]. Indeed, analytical approaches are generally rather limited, only the simply supported boundary conditions at ends are considered in the majority of the analytical studies on the stiffened plate and shell structures. There are rather few studies on the free vibration of the stiffened functionally graded cylindrical shell with different boundary conditions [15, 47, 54-56]. For example, Loy et al. [15] published a study on free vibration of isotropic cylindrical shell with various boundary conditions using generalized differential quadrature method. Wang and Wu recently published a study on free vibration of functionally graded porous (FGP) cylindrical shell structures subjected to different boundary conditions et ends [57], the natural frequency of the shell was obtained by utilizing the sinusoidal shear deformation theory (SSDT) and Rayleigh-Ritz method.

From the above reviews, this study focuses on the free vibration analysis of the stiffened functionally graded cylindrical shell with several boundary conditions resting on elastic foundation. Herein, the Lekhnitsky smeared stiffeners technique is used to smear the stiffeners into an equivalence layer of the cylindrical shell. Although this approach has several limitations, it is still a simple way and having a low computational cost. To obtain the natural frequency of the stiffened functionally graded cylindrical shell with several boundary conditions, the Galerkin method is used with the beam functions of axial displacement fields. Due to the limitation of the proposed method, only three types of boundary conditions of the shell are considered as: simply supported-simply supported, clamped-simply supported, and clamped-clamped boundary conditions. In the investigation sections, the influences of volume fraction index, boundary conditions, geometrical ratios, and elastic foundation coefficients on the fundamental frequency of the stiffened FG cylindrical shell are given in details.

\section{Material properties and theoretical formulations}

In this section, the formulations and governing equations of a stiffened functionally graded $(\mathrm{FG})$ cylindrical shell resting on elastic foundation will be presented. The geometric dimensions of the cylindrical shell structure as follows: $R$ is radius, $h$ is thickness, and $L$ is length of the FG cylindrical shell structure in the coordinate system $(x, \theta, z)$. The functionally graded cylindrical shell structure is reinforced by rings (circumferential stiffeners) and stringers (longitudinal stiffeners), as shown in Fig. 1.

The material properties of the cylindrical shell vary continuously and smoothly throughout the thickness direction according to simple power-law distribution of the volume fraction of constituents. It can be assumed that the modulus of elasticity, mass of density and Poisson's ratio of the shell material as [58]:

$$
\begin{aligned}
& E(z)=\left(E_{1}-E_{2}\right)\left(\frac{z}{h}+\frac{1}{2}\right)^{p}+E_{2} \\
& \rho(z)=\left(\rho_{1}-\rho_{2}\right)\left(\frac{z}{h}+\frac{1}{2}\right)^{p}+\rho_{2} \\
& \nu(z)=\left(v_{1}-v_{2}\right)\left(\frac{z}{h}+\frac{1}{2}\right)^{p}+v_{2}
\end{aligned}
$$

where $p$ is volume fraction index; and $E_{1}, \rho_{1}, v_{1}$ are modulus of elasticity, mass of density and Poison's ratio of the

Fig. 1 Geometry and coordinate system of the functionally graded cylindrical shell with stiffeners
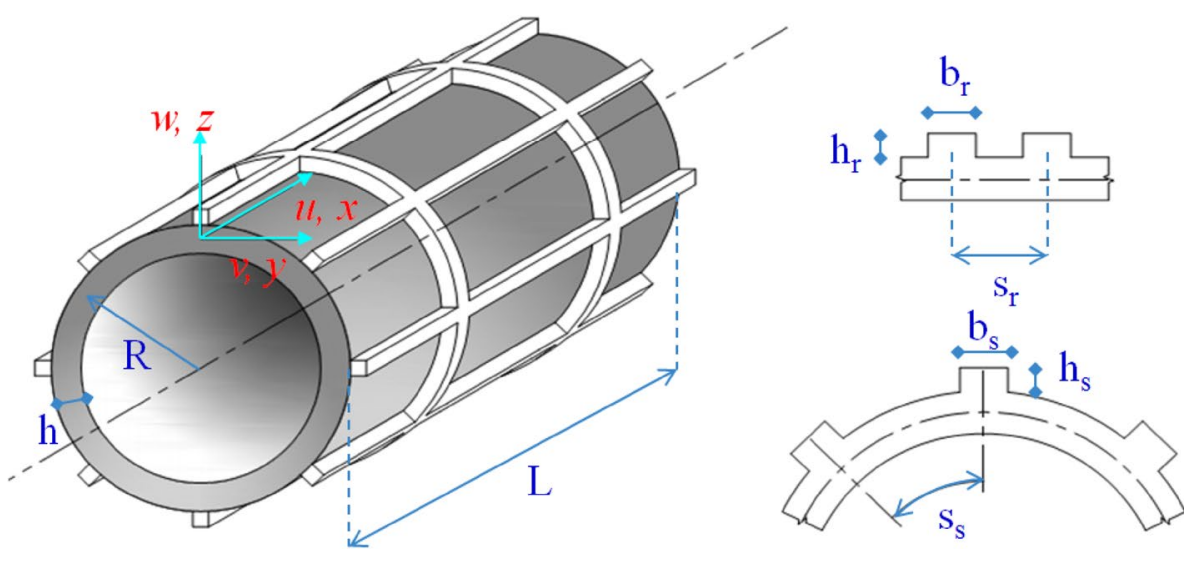
material at the outer surface of the cylindrical shell, respectively. By contrast, $E_{2}, \rho_{2}, v_{2}$ are modulus of elasticity, mass of density and Poison's ratio of the material at the inner surface of the FG cylindrical shell.

According to the first-order shear deformation theory (FSDT), the displacement field of a point located in the middle surface of the functionally graded cylindrical shell structure is defined as $[59,60]$ :

$$
\begin{aligned}
u(x, \theta, z, t) & =u_{0}(x, \theta, t)+z . \phi_{x}(x, \theta, t) \\
v(x, \theta, z, t) & =v_{0}(x, \theta, t)+z . \phi_{\theta}(x, \theta, t) \\
w(x, \theta, z, t) & =w_{0}(x, \theta, t)
\end{aligned}
$$

herein $u_{0}, v_{0}, w_{0}$ are the components of displacement field of a point located in the middle surface of the cylindrical shell structure. Symbols $\phi_{x}(x, \theta, t), \phi_{\theta}(x, \theta, t)$ are the rotation angle of the normal of middle surface to the axes $\theta, x$ respectively.

The relationships between strains and displacement components of the shell are in the form:

$$
\begin{aligned}
\varepsilon_{x} & =\varepsilon_{x}^{0}+z . \kappa_{x} \\
\varepsilon_{\theta} & =\varepsilon_{\theta}^{0}+z . \kappa_{\theta} \\
\gamma_{x \theta} & =\gamma_{x \theta}^{0}+z . \kappa_{x \theta} \\
\gamma_{\theta z} & =\gamma_{\theta z}^{0} \\
\gamma_{x z} & =\gamma_{x z}^{0}
\end{aligned}
$$

in which: $\varepsilon_{x}^{0}=\frac{\partial u_{0}}{\partial x} ; \kappa_{x}=\frac{\partial \phi_{x}}{\partial x} ; \varepsilon_{\theta}^{0}=\frac{\partial v_{0}}{R \partial \theta}+\frac{w_{0}}{R} ; \kappa_{\theta}=\frac{\partial \phi_{\theta}}{R \partial \theta}$; $\gamma_{x \theta}^{0}=\frac{\partial u_{0}}{R \partial \theta}+\frac{\partial v_{0}}{\partial x} ; \quad \kappa_{x \theta}=\frac{\partial \phi_{x}}{R \partial \theta}+\frac{\partial \phi_{\theta}}{\partial x} ; \quad \gamma_{\theta z}^{0}=\phi_{\theta}+\frac{\partial w_{0}}{R \partial \theta}-\frac{v_{0}}{R} ;$ $\gamma_{x z}^{0}=\phi_{x}+\frac{\partial w_{0}}{\partial x}$

In present study, it is assumed that the stiffeners' dimensions are small in comparison with the shell's geometric dimensions; hence, the wrist of stiffeners can be neglected. On the other hand, the isotropic stiffeners are made from the same material with the shell surfaces that they attached, so the connection between the stiffeners and the shell are continuous ideally. Furthermore, it is assumed that the stiffeners are in the uniaxial stress state, omitting the wrist of stiffeners, using the Lekhnitsky smeared stiffeners technique, the force and moment resultants of the stiffened FG cylindrical shell can be obtained in the form as $[46,61-63]$ :

$$
\begin{aligned}
& N_{x}=\left(A_{11}+\frac{E_{s} A_{s}}{s_{s}}\right) \varepsilon_{x}^{0}+A_{12} \varepsilon_{\theta}^{0}+\left(B_{11}+\frac{E_{s} A_{s} z_{s}}{s_{s}}\right) \kappa_{x}+B_{12} \kappa_{\theta} \\
& N_{\theta}=A_{12} \varepsilon_{x}^{0}+\left(A_{22}+\frac{E_{r} A_{r}}{s_{r}}\right) \varepsilon_{\theta}^{0}+B_{12} \kappa_{x}+\left(B_{22}+\frac{E_{r} A_{r} z_{r}}{s_{r}}\right) \kappa_{\theta} \\
& N_{x \theta}=A_{66} \gamma_{x \theta}^{0}+B_{66} \kappa_{x \theta}
\end{aligned}
$$

$$
\begin{aligned}
M_{x} & =\left(B_{11}+\frac{E_{s} A_{s} z_{s}}{s_{s}}\right) \varepsilon_{x}^{0}+B_{12} \varepsilon_{\theta}^{0}+\left(D_{11}+\frac{E_{s} I_{s}}{s_{s}}\right) \kappa_{x}+D_{12} \kappa_{\theta} \\
M_{\theta} & =B_{12} \varepsilon_{x}^{0}+\left(B_{22}+\frac{E_{r} A_{r} z_{r}}{s_{r}}\right) \varepsilon_{\theta}^{0}+D_{12} \kappa_{x}+\left(D_{22}+\frac{E_{r} I_{r}}{s_{r}}\right) \kappa_{\theta} \\
M_{x \theta} & =B_{66} \gamma_{x \theta}^{0}+D_{66} \kappa_{x \theta}
\end{aligned}
$$

$$
\left\{\begin{array}{l}
Q_{\theta}=K_{s}\left(A_{44}+\frac{G_{r} A_{r}}{s_{r}}\right) \gamma_{\theta z} \\
Q_{x}=K_{s}\left(A_{55}+\frac{G_{s} A_{s}}{s_{s}}\right) \gamma_{x z}
\end{array}\right.
$$

$$
\begin{aligned}
A_{11}= & A_{22}=\int_{-h / 2}^{h / 2} \frac{E(z)}{1-v^{2}(z)} d z ; \quad B_{11}=B_{22}=\int_{-h / 2}^{h / 2} \frac{E(z)}{1-v^{2}(z)} z d z ; \quad D_{11}=D_{22}=\int_{-h / 2}^{h / 2} \frac{E(z)}{1-v^{2}(z)} z^{2} d z \\
A_{12}= & \int_{-h / 2}^{h / 2} \frac{v(z) E(z)}{1-v^{2}(z)} d z ; \quad B_{12}=\int_{-h / 2}^{h / 2} \frac{v(z) E(z)}{1-v^{2}(z)} z d z ; \quad D_{12}=\int_{-h / 2}^{h / 2} \frac{v(z) E(z)}{1-v^{2}(z)} z^{2} d z \\
A_{66}= & \int_{-h / 2}^{h / 2} \frac{E(z)}{2[1+v(z)]} d z ; \quad B_{66}=\int_{-h / 2}^{h / 2} \frac{E(z)}{2[1+v(z)]} z d z ; \quad D_{66}=\int_{-h / 2}^{h / 2} \frac{E(z)}{2[1+v(z)]} z^{2} d z \\
A_{44}= & A_{55}=\int_{-h / 2}^{h / 2} \frac{E(z)}{2[1+v(z)]} d z \quad \\
I_{s}= & \frac{b_{s} h_{s}^{3}}{12}+A_{s} z_{s}^{2} ; I_{r}=\frac{b_{r} h_{r}^{3}}{12}+A_{r} z_{r}^{2} ; \quad z_{s}= \pm \frac{h_{s}+h}{2} ; z_{r}= \pm \frac{h_{r}+h}{2}
\end{aligned}
$$


Herein, let $E_{s}, G_{s}$ and $E_{r}, G_{r}$ denote the elastic modulus, the shear modulus of the stringer and ring materials, respectively. The height and width of stringer (ring) are $h_{s}$ and $b_{s}$ $\left(h_{r}\right.$ and $b_{r}$ ) respectively. Cross-sectional areas of stringer and ring are $A_{s}$ and $A_{r}$, respectively. Let $s_{s}$ and $s_{r}$ denote distances between stringers and between rings, whereas $z_{s}$ and $z_{r}$ represent distances from the centroid of the stringer and ring to the middle surface of the cylindrical shell, respectively.

By applying Hamilton's principle, the governing equations of the stiffened functionally graded cylindrical shell resting on Winkler-Pasternak foundation are obtained as follows $[43,59,60]$ :

$$
\begin{aligned}
& \frac{\partial N_{x}}{\partial x}+\frac{\partial N_{\theta x}}{R \partial \theta}=J_{0} \ddot{u}_{0}+J_{1} \ddot{\phi}_{x} ; \quad \frac{\partial N_{x \theta}}{\partial x}+\frac{\partial N_{\theta}}{R \partial \theta}+\frac{Q_{\theta}}{R}=J_{0} \ddot{v}_{0}+J_{1} \ddot{\phi}_{\theta} \\
& \frac{\partial Q_{x}}{\partial x}+\frac{\partial Q_{\theta}}{R \partial \theta}-\frac{N_{\theta}}{R}-K_{w} w_{0}+K_{p} \nabla^{2} w_{0}=J_{0} \ddot{w}_{0} \\
& \frac{\partial M_{x}}{\partial x}+\frac{\partial M_{\theta x}}{R \partial \theta}-Q_{x}=J_{1} \ddot{u}_{0}+J_{2} \ddot{\phi}_{x} ; \quad \frac{\partial M_{x \theta}}{\partial x}+\frac{\partial M_{\theta}}{R \partial \theta}-Q_{\theta}=J_{1} \ddot{v}_{0}+J_{2} \ddot{\phi}_{\theta}
\end{aligned}
$$

in which: $\nabla^{2}=\frac{\partial^{2}}{\partial x^{2}}+\frac{1}{R^{2}} \frac{\partial^{2}}{\partial \theta^{2}}$ is Laplace operator.

Factors: $K_{w}$ and $K_{p}$ are the stiffness coefficients of the elastic foundation; The moments of inertia $J_{i}=\int_{-h / 2}^{h / 2} \rho_{e q}(z) z^{i} d z(i=0,1,2)$ with $\rho_{e q}=\rho(z)+\frac{\rho_{s} A_{s}}{s_{s} h}+\frac{\rho_{r} A_{r}}{s_{r} h}$.

Equation (7) can be expressed in terms of the displacement fields $\left(u_{0}, v_{0}, w_{0}, \phi_{x}, \phi_{\theta}\right)$ by using the expressions of Eqs. (3)-(6) as follows:

$L_{11} u_{0}+L_{12} v_{0}+L_{13} w_{0}+L_{14} \phi_{x}+L_{15} \phi_{\theta}=0$
$L_{21} u_{0}+L_{22} v_{0}+L_{23} w_{0}+L_{24} \phi_{x}+L_{25} \phi_{\theta}=0$
$L_{31} u_{0}+L_{32} v_{0}+L_{33} w_{0}+L_{34} \phi_{x}+L_{35} \phi_{\theta}=0$
$L_{41} u_{0}+L_{42} v_{0}+L_{43} w_{0}+L_{44} \phi_{x}+L_{45} \phi_{\theta}=0$
$L_{51} u_{0}+L_{52} v_{0}+L_{53} w_{0}+L_{54} \phi_{x}+L_{55} \phi_{\theta}=0$

where $L_{i j}(i, j=1,2, \ldots, 5)$ are differential operators given in "Appendix".

\section{Analytical solution}

In this section, an analytical solution for the stiffened functionally graded cylindrical shell resting on elastic foundation with several boundary conditions will be presented.

First step, to solve the problem on free vibration of the cylindrical shell structure, the displacement functions are chosen as $[57,64,65]$ :

$$
\begin{aligned}
& u_{0}(x, \theta, t)=\sum_{m=1}^{\infty} \sum_{m=1}^{\infty} A_{m n} \phi_{m}^{u}(x) \phi_{n}^{u}(\theta) \cos (\omega t) \\
& v_{0}(x, \theta, t)=\sum_{m=1}^{\infty} \sum_{m=1}^{\infty} B_{m n} \phi_{m}^{v}(x) \phi_{n}^{v}(\theta) \cos (\omega t) \\
& w_{0}(x, \theta, t)=\sum_{m=1}^{\infty} \sum_{m=1}^{\infty} C_{m n} \phi_{m}^{w}(x) \phi_{n}^{w}(\theta) \cos (\omega t) \\
& \phi_{x}(x, \theta, t)=\sum_{m=1}^{\infty} \sum_{m=1}^{\infty} D_{m n} \phi_{m}^{\phi_{x}}(x) \phi_{n}^{\phi_{x}}(\theta) \cos (\omega t) \\
& \phi_{\theta}(x, \theta, t)=\sum_{m=1}^{\infty} \sum_{m=1}^{\infty} E_{m n} \phi_{m}^{\phi_{\theta}}(x) \phi_{n}^{\phi_{\theta}}(\theta) \cos (\omega t)
\end{aligned}
$$

in which:

$\phi_{n}^{u}(\theta)=\phi_{n}^{w}(\theta)=\phi_{n}^{\phi_{x}}(\theta, t)=\cos (n \theta)$
$\phi_{n}^{v}(\theta)=\phi_{n}^{\phi_{\theta}}(\theta)=\sin (n \theta)$

where $A_{m n}, B_{m n}, C_{m n}, D_{m n}, E_{m n}$ are unknowns, $m$ and $n$ are natural numbers and expressing the number of half waves in the longitudinal and circumferential directions of the cylindrical shell, respectively. It can be noted that $\phi_{m}^{k}(x)\left(k=v, w, \phi_{\theta}\right)$ is the function in the longitudinal direction, satisfying the geometric boundary conditions, and can be written in the form:

$$
\begin{gathered}
\phi_{m}^{k}(x)=T_{1} \cosh \left(\frac{\lambda_{m} x}{L}\right)+T_{2} \cos \left(\frac{\lambda_{m} x}{L}\right) \\
-\mu_{m}\left[T_{3} \sinh \left(\frac{\lambda_{m} x}{L}\right)+T_{4} \sin \left(\frac{\lambda_{m} x}{L}\right)\right]
\end{gathered}
$$

The remaining functions $\phi_{m}^{i}(x)\left(i=u, \phi_{x}\right)$ can be given by expressions: $\phi_{m}^{i}(x)=\partial \phi_{m}^{k}(x) / \partial x$. Coefficients $T_{1}, T_{2}, T_{3}, T_{4}, \lambda_{m}$ and $\mu_{m}$ in Eq. (11) with several boundary conditions at ends of the stiffened FG cylindrical shell are given as [57]:

Clamped-clamped (C-C):

$$
\begin{aligned}
& T_{1}=1, T_{2}=-1, T_{3}=1, T_{4}=-1, \\
& \mu_{m}=\frac{\cosh \lambda_{m}-\cos \lambda_{m}}{\sinh \lambda_{m}-\sin \lambda_{m}}, \quad \lambda_{m}=(2 m+1) \pi / 2
\end{aligned}
$$

Clamped-simply supported (C-S):

$T_{1}=1, T_{2}=-1, T_{3}=1, T_{4}=-1$,

$$
\mu_{m}=\frac{\cosh \lambda_{m}-\cos \lambda_{m}}{\sinh \lambda_{m}-\sin \lambda_{m}}, \quad \lambda_{m}=(4 m+1) \pi / 4
$$

Simply supported $(S-S)$ :

$$
T_{1}=0, T_{2}=0, T_{3}=0, T_{4}=-1, \quad \mu_{m}=1, \quad \lambda_{m}=m \pi
$$


Next, substituting expressions from Eq. (9) into Eq. (8), and then applying the Galerkin method for the obtained results, we have equations as follows $[64,65]$ :

$\int_{t} \int_{\theta} \int_{x}\left(L_{11} u_{0}+L_{12} v_{0}+L_{13} w_{0}+L_{14} \phi_{x}+L_{15} \phi_{\theta}\right) u_{0} d x d \theta d t=0$

$\int_{t} \int_{\theta} \int_{x}\left(L_{21} u_{0}+L_{22} v_{0}+L_{23} w_{0}+L_{24} \phi_{x}+L_{25} \phi_{\theta}\right) v_{0} d x d \theta d t=0$

$\int_{t} \int_{\theta} \int_{x}\left(L_{31} u_{0}+L_{32} v_{0}+L_{33} w_{0}+L_{34} \phi_{x}+L_{35} \phi_{\theta}\right) w_{0} d x d \theta d t=0$

$\int_{t} \int_{\theta} \int_{x}\left(L_{41} u_{0}+L_{42} v_{0}+L_{43} w_{0}+L_{44} \phi_{x}+L_{45} \phi_{\theta}\right) \phi_{x} d x d \theta d t=0$

$\int_{t} \int_{\theta} \int_{x}\left(L_{51} u_{0}+L_{52} v_{0}+L_{53} w_{0}+L_{54} \phi_{x}+L_{55} \phi_{\theta}\right) \phi_{\theta} d x d \theta d t=0$
Afterward, to perform the integration for Eq. (12), the obtained results can be written in the matrix form as:

$\left([K]_{5 \times 5}-\omega^{2}[M]_{5 \times 5}\right)\{\delta\}_{5 \times 1}=\{0\}$

where $\{\delta\}_{5 \times 1}=\left\{A_{m n}, B_{m n}, C_{m n}, D_{m n}, E_{m n}\right\}^{T}$. Factors $K_{i j}$ and $M_{i j}$ can be obtained by using MATLAB software. Doing the solution of eigenvalue problem of Eq. (13), we can get natural frequencies of free vibration of the stiffened functionally graded cylindrical shell resting on elastic foundation, and the corresponding vibration mode.

\section{Result and discussions}

In the following examples, the geometric and material properties for the functionally graded cylindrical shell and stiffeners used are in Table 1.
Table 1 The geometric and material properties for the stiffened FG cylindrical shell structure

\begin{tabular}{|c|c|c|c|c|c|c|}
\hline \multirow{2}{*}{$\begin{array}{l}\text { Characteristics } \\
\text { Type of stiffeners }\end{array}$} & \multicolumn{6}{|c|}{ Geometrical data } \\
\hline & Unstiffened & Stringers & Rings & Stringers & $\begin{array}{l}\text { Orthogonal } \\
\text { rings/string- } \\
\text { ers }\end{array}$ & $\begin{array}{l}\text { Orthogonal } \\
\text { rings/string- } \\
\text { ers }\end{array}$ \\
\hline Model & $\mathrm{R} 1$ & $\mathrm{R} 2$ & R3 & $\mathrm{R} 4$ & R5 & R6 \\
\hline Number of stiffeners & & 60 & 19 & 04 & $13 / 20$ & $05 / 10$ \\
\hline Radius (m) & 1 & 0.242 & 0.49759 & 0.1945 & 0.203 & 0.2 \\
\hline Thickness (m) & 0.05 & $6 E-4$ & $1.65 E-3$ & $4.64 \mathrm{E}-4$ & $2.04 \mathrm{E}-3$ & 0.002 \\
\hline Length (m) & 20 & 0.6096 & 0.3945 & 0.9868 & 0.813 & 1 \\
\hline Height of stiffeners (m) & & 0.00702 & 0.005334 & 0.0101 & $0.006 / 0.006$ & $0.006 / 0.006$ \\
\hline Width of stiffeners (m) & & 0.002554 & 0.003175 & 0.00104 & $0.004 / 0.008$ & $0.002 / 0.002$ \\
\hline $\mathrm{E}_{0}\left(\mathrm{~N} / \mathrm{m}^{2}\right)$ & & $6.9 \mathrm{E}+10$ & $6.9 \mathrm{E}+10$ & $2.00 E+11$ & $2.07 \mathrm{E}+11$ & $2.00 \mathrm{E}+11$ \\
\hline$v_{0}$ & & 0.3 & 0.3 & 0.3 & 0.3 & 0.3 \\
\hline$\rho_{0}\left(\mathrm{~kg} / \mathrm{m}^{3}\right)$ & & 2714 & 2762 & 7770 & 7430 & 5700 \\
\hline$E_{1}\left(\mathrm{~N} / \mathrm{m}^{2}\right)$ & $2.07788 \mathrm{E}+11$ & & & & & $2.00 \mathrm{E}+11$ \\
\hline$v_{1}$ & 0.317756 & & & & & 0.3 \\
\hline$\rho_{1}\left(\mathrm{~kg} / \mathrm{m}^{3}\right)$ & 8166 & & & & & 5700 \\
\hline$E_{2}\left(\mathrm{~N} / \mathrm{m}^{2}\right)$ & $2.05098 \mathrm{E}+11$ & & & & & $7.0 \mathrm{E}+10$ \\
\hline$v_{2}$ & 0.31 & & & & & 0.3 \\
\hline$\rho_{2}\left(\mathrm{~kg} / \mathrm{m}^{3}\right)$ & 8900 & & & & & 2702 \\
\hline Stiffening type & & External & External & Internal & Internal & External \\
\hline
\end{tabular}

Table 2 Comparison the natural frequency of the stiffened isotropic cylindrical shell

\begin{tabular}{|c|c|c|c|c|c|c|c|c|c|}
\hline \multirow{2}{*}{\multicolumn{2}{|c|}{$\begin{array}{l}\text { Mode } \\
\text { number }\end{array}$}} & \multicolumn{8}{|c|}{ Natural frequencies $(\mathrm{Hz})$} \\
\hline & & \multicolumn{2}{|c|}{ R2 (stringers) } & \multicolumn{2}{|l|}{ R3 (rings) } & \multicolumn{2}{|c|}{ R4 (stringers) } & \multicolumn{2}{|c|}{ R5 (orth. stiffened) } \\
\hline$m$ & $n$ & Ref. [41] & Present & Ref. [41] & Present & Ref. [41] & Present & Ref. [41] & Present \\
\hline \multirow[t]{5}{*}{1} & 1 & 1141 & 1143.1 & 1204 & 1225.6 & 778 & 778.1 & 942 & 936.3 \\
\hline & 2 & 674 & 672.3 & 1587 & 1584.4 & 317 & 317.2 & 439 & 436.8 \\
\hline & 3 & 427 & 425.3 & 4462 & 4391.5 & 159 & 159.3 & 337 & 330.8 \\
\hline & 4 & 296 & 294.5 & 8559 & 8311.9 & 99.6 & 101.6 & 482 & 476.7 \\
\hline & 5 & 225 & 223.2 & 13,780 & $13,188.3$ & 91.5 & 91.4 & 740 & 737.6 \\
\hline
\end{tabular}




\subsection{Validation of present study}

Firstly, in order to verify the natural frequency of the functionally graded cylindrical shell with stiffeners, a comparison between the present results and those reported by Mustafa and Ali [41], geometric and material properties used are R2, R3, R4 and R5 models in Table 1, the comparison results between them are presented in Table 2 . It can be pointed out that the maximum discrepancy is only $4.29 \%$ with R3 model. It can be noted that the publication of Mustafa and Ali used the energy method and Flugge's shell theory with simply supported boundary conditions at ends [41].

Besides, the fundamental frequencies of the stiffened FG cylindrical shell from the present study are compared with those of Tran and Nguyen [46] using Navier-type solution. Material and geometric properties used is R6 model in Table 1, with the notice that the stiffeners' dimensions used are $b_{s}=b_{r}=0.002 \mathrm{~m}, h_{s}=h_{r}=0.012 \mathrm{~m}$. The results of the comparison are listed in Table 3 , it can be seen that the discrepancies is relatively small, maximum error is $0.1 \%$.

Finally, to validate the natural frequencies of cylindrical shell with several boundary conditions (simply supported-simply supported, clamped-simply supported and clamped-clamped). One comparison on the non-dimensional natural frequency of the isotropic cylindrical shell between the present results with those of Wang and Wu [57] using the sinusoidal shear deformation theory and Rayleigh-Ritz method are carried out. The comparison

Table 3 Comparison of the fundamental frequency of stiffened FG cylindrical shell structure

\begin{tabular}{llll}
\hline$p$ & \multicolumn{3}{l}{ Fundamental frequencies $(\mathrm{Hz})$} \\
\cline { 2 - 4 } & Ref. [46] & Present & Discrepancy (\%) \\
\hline 0 & 369.13 & 368.78 & 0.10 \\
3 & 356.04 & 356.11 & 0.02 \\
20 & 344.93 & 344.90 & 0.01 \\
\hline
\end{tabular}

results are shown in Table 4, the non-dimensional natural frequency used is $\varpi=R \omega \sqrt{\left(1-v^{2}\right) \rho / E}$. It can be shown that the maximum discrepancy is $0.61 \%$.

From above verifications, it can be found that the present results have small differences in comparison with the works of Mustafa and Ali [41], Tran and Nguyen [46], and Wang and Wu [57]. It can be concluded that the program codes and formulations of the present study on the free vibration of the stiffened functionally graded cylindrical shell resting on elastic foundation is reliable.

\subsection{Numerical investigations}

In investigations, unless otherwise specified, geometric and material properties used are in R6 model of Table 1. In this model, the functionally graded cylindrical shell are made of functional graded materials $\mathrm{Al} / \mathrm{ZrO}_{2}$.

Next, some investigations related to the influences of volume fraction index, geometric ratios, boundary conditions, elastic foundation parameters on the fundamental frequency of the stiffened FG circular cylindrical shell are presented in the following subsections.

\subsubsection{Effects of volume fraction index}

Figure 2 illustrates the variation of fundamental frequency of the stiffened FG cylindrical shell resting on Winkler and Pasternak foundation versus the volume fraction index with three boundary conditions: simply supported-simply supported (SS), clamped-simply supported (CS), clamped-clamped (CC).

As Fig. 2 shown, the fundamental frequencies have some slightly fluctuations as the volume fraction index increase. Besides, the influences of volume fraction index on the fundamental frequency of the cylindrical shell structure are more clearly as the elastic foundation parameters $K_{w}\left(\mathrm{~N} / \mathrm{m}^{3}\right), K_{p}(\mathrm{~N} / \mathrm{m})$ rise up.

Table 4 Comparison of non-dimensional natural frequency for unstiffened isotropic cylindrical shell

\begin{tabular}{|c|c|c|c|c|c|c|c|c|c|}
\hline \multirow[t]{3}{*}{$\mathrm{n}$} & \multicolumn{9}{|c|}{ Boundary conditions } \\
\hline & \multicolumn{3}{|c|}{$\begin{array}{l}\text { Simply supported-simply supported } \\
(m=1, h / R=1 / 100, L / R=20)\end{array}$} & \multicolumn{3}{|c|}{$\begin{array}{l}\text { Clamped-clamped }(m=1, h / R=2 / 1000, \\
L / R=20)\end{array}$} & \multicolumn{3}{|c|}{$\begin{array}{l}\text { Clamped-simply supported }(m=1, \\
h / R=2 / 1000, L / R=20)\end{array}$} \\
\hline & Ref. [57] & Present & Discrepancy (\%) & Ref. [57] & Present & Discrepancy (\%) & Ref. [57] & Present & Discrepancy (\%) \\
\hline 1 & 0.0161 & 0.0160 & 0.61 & 0.0340 & 0.0340 & 0.05 & 0.024830 & 0.024721 & 0.44 \\
\hline 2 & 0.0094 & 0.0094 & 0.42 & 0.0119 & 0.0119 & 0.10 & 0.008411 & 0.008379 & 0.38 \\
\hline 3 & 0.0221 & 0.0221 & 0.12 & 0.0072 & 0.0072 & 0.38 & 0.005897 & 0.005884 & 0.23 \\
\hline 4 & 0.0421 & 0.0420 & 0.17 & 0.0090 & 0.0090 & 0.28 & 0.008717 & 0.008704 & 0.15 \\
\hline 5 & 0.0680 & 0.0679 & 0.17 & 0.0137 & 0.0138 & 0.37 & 0.013682 & 0.013663 & 0.14 \\
\hline
\end{tabular}




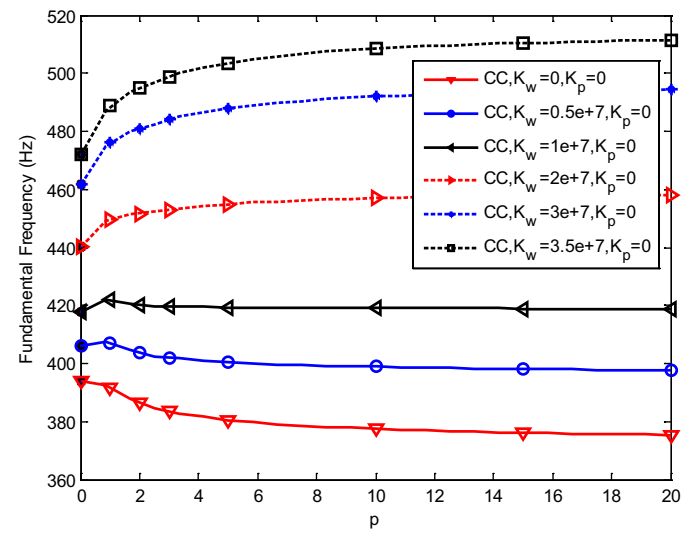

(a) Winkler foundation, clamped - clamped boundary

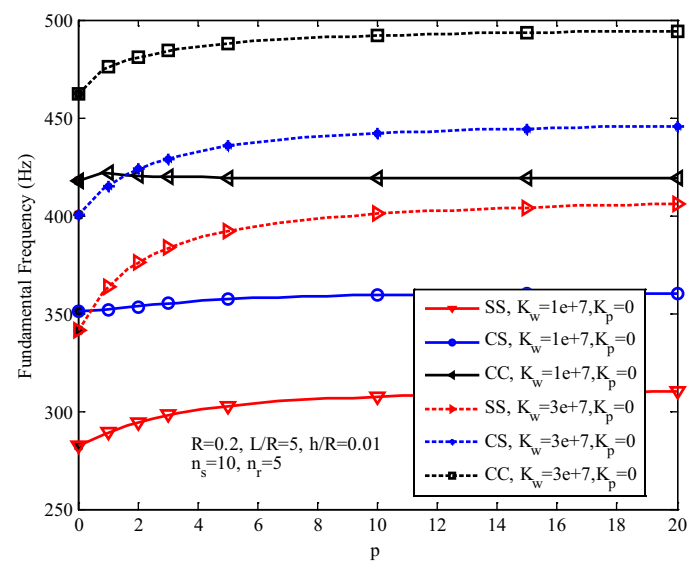

(c) Winkler foundation

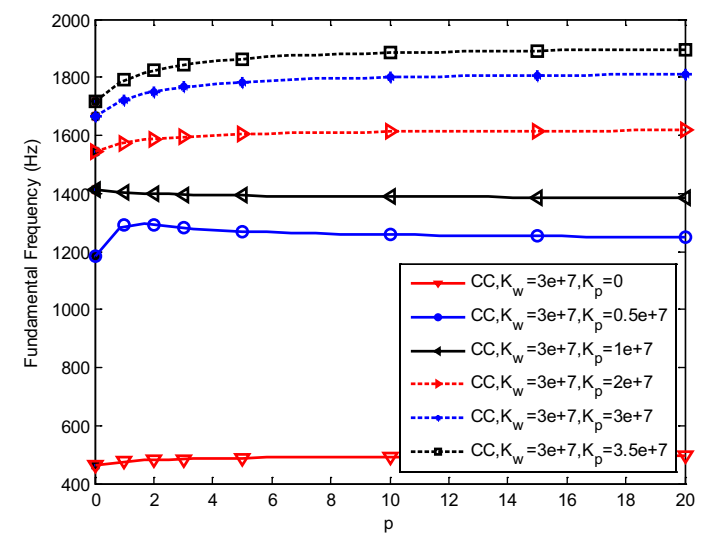

(b) Pasternak foundation, clamped - clamped boundary

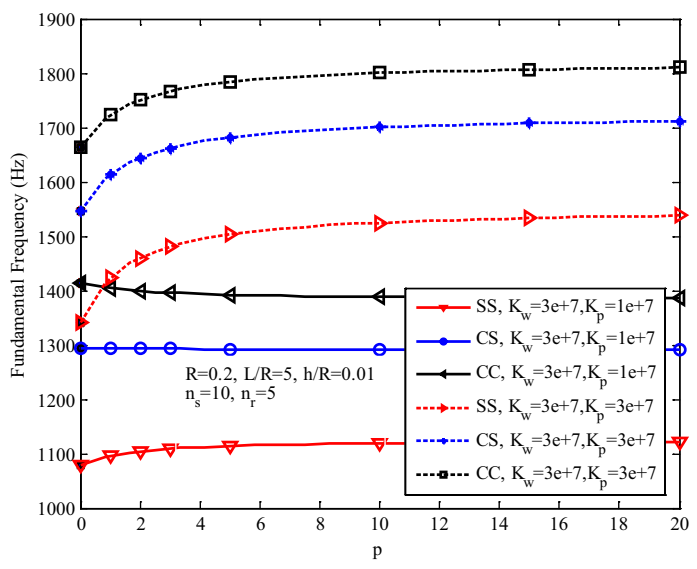

(d) Pasternak foundation

Fig. 2 The variation of fundamental frequency with respect to volume fraction index

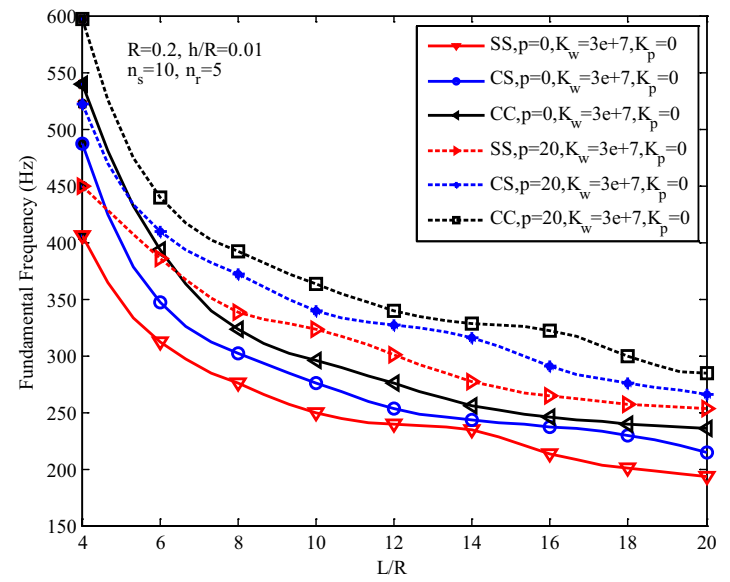

(a) Winkler foundation

$$
K_{w}=3 \cdot 10^{7} \mathrm{~N} / \mathrm{m}^{3} ; K_{p}=0
$$

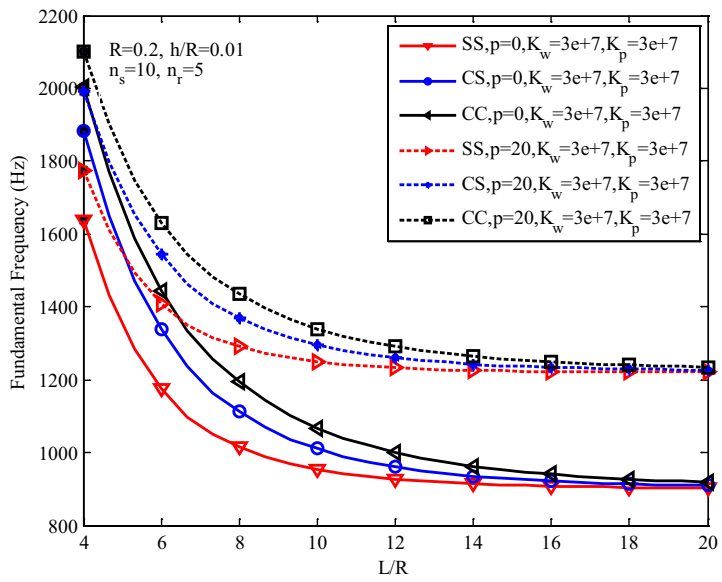

(b) Pasternak foundation

$K_{w}=3.10^{7} \mathrm{~N} / \mathrm{m}^{3} ; K_{p}=3.10^{7} \mathrm{~N} / \mathrm{m}$

Fig. 3 Influence of L/R ratio on the natural fundamental frequency 
For boundary conditions, it can be seen that the clamped-clamped boundary condition shell produces fundamental frequencies higher than those of other boundary conditions. This phenomenon is because of the clamped-clamped boundary condition enhances the cylindrical shell's stiffness.

\subsubsection{Effects of geometric ratios and boundary conditions}

This section, the influences of geometric ratios $(L / R, h / R)$ and boundary conditions (CC, CS, SS) on the fundamental frequency of the stiffened functionally graded cylindrical shell resting on elastic foundation will be presented.

Figure 3 shows the variation of fundamental frequency with respect to $L / R$ ratio of the stiffened

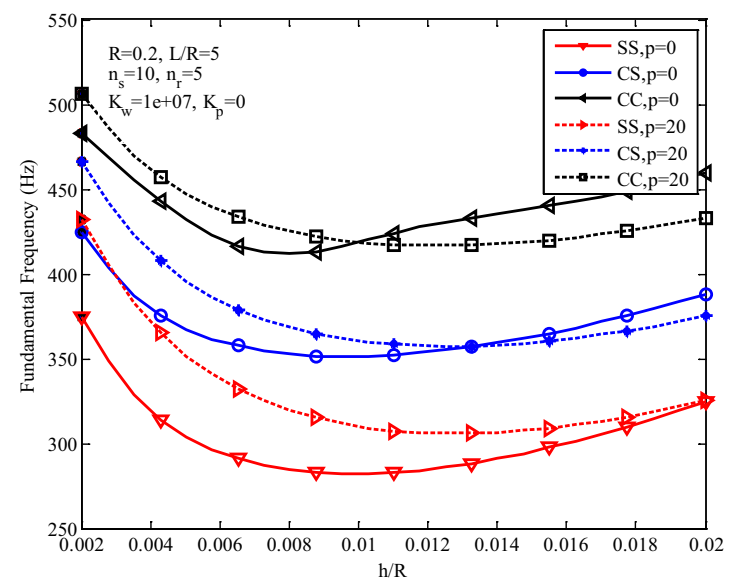

(a) Winkler foundation

$$
K_{w}=1.10^{7} \mathrm{~N} / \mathrm{m}^{3} ; K_{p}=0
$$

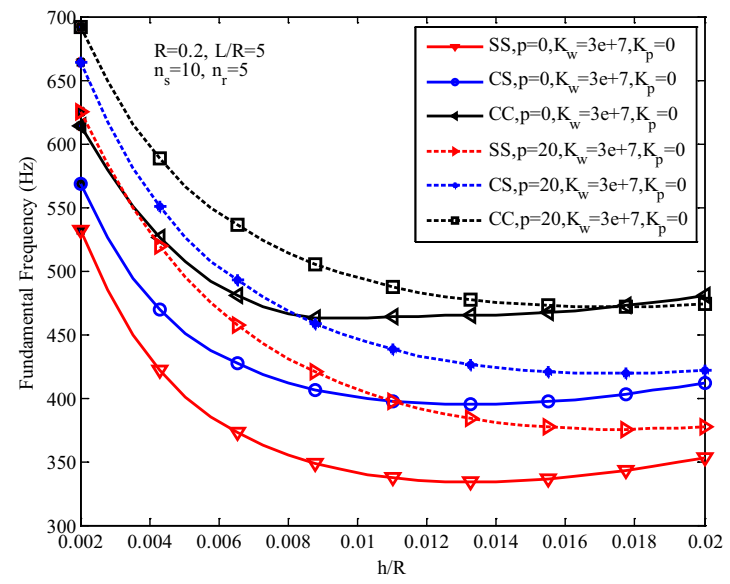

(c) Winkler foundation

$$
K_{w}=3.10^{7} \mathrm{~N} / \mathrm{m}^{3} ; K_{p}=0
$$

functionally graded cylindrical shell resting on elastic foundations, three types of boundary conditions namely clamped-clamped (CC), clamped-simply supported (CS), and simply supported-simply supported (SS) are illustrated. In particular, one example is presented the results of the stiffened FG cylindrical shell resting on Winkler foundation in Fig. 3a, whereas the results for the Pasternak foundation are plotted in Fig. $3 \mathrm{~b}$.

As the graphs in Fig. 3, it can be seen that the fundamental frequencies of the stiffened FG cylindrical shell generally fall down as the ratio $L / R$ increase at all cases. The smaller the ratios $L / R$ are, the faster the fundamental frequency of stiffened FG cylindrical shell decrease. Besides, the shell's small $L / R$ ratio is sensitive on fundamental frequency of the stiffened FG cylindrical

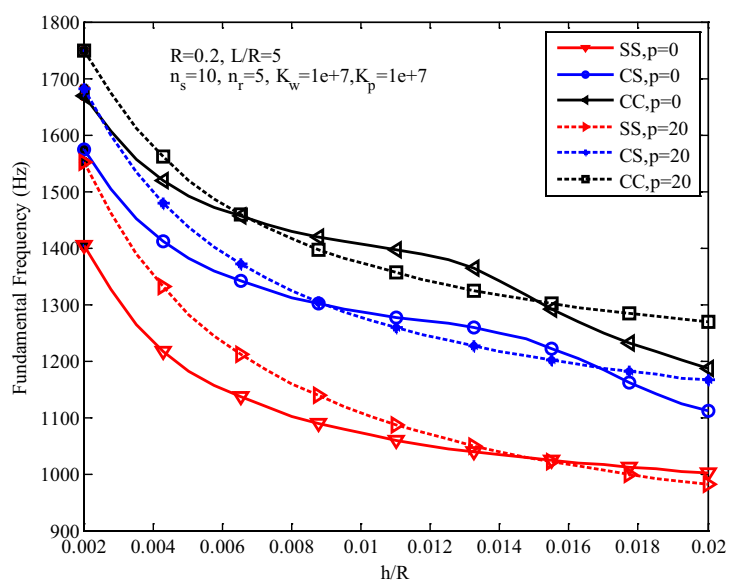

(b) Pasternak foundation

$$
K_{w}=1.10^{7} \mathrm{~N} / \mathrm{m}^{3} ; K_{p}=1.10^{7} \mathrm{~N} / \mathrm{m}
$$

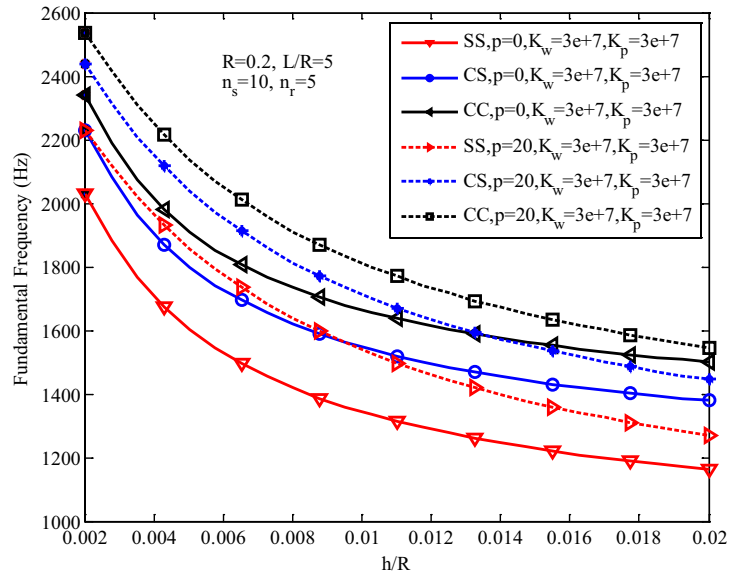

(d) Pasternak foundation

$$
K_{w}=3.10^{7} \mathrm{~N} / \mathrm{m}^{3} ; K_{p}=3.10^{7} \mathrm{~N} / \mathrm{m}
$$

Fig. 4 Influence of $h / R$ ratio on the fundamental frequency 
shell. Moreover, Fig. $3 \mathrm{~b}$ demonstrates that when the geometric ratio $L / R>18$ and Pasternak foundation $K_{w}=3.10^{7} \mathrm{~N} / \mathrm{m}^{3}, K_{p}=3.10^{7} \mathrm{~N} / \mathrm{m}$, the fundamental frequencies are almost identical at all boundary conditions, the effects of the boundary conditions on the fundamental frequency of the shell are small.

Figure 4 shows the variation of fundamental frequency of the stiffened FG cylindrical shell with respect to $h / R$ ratio, and corresponding to three types of boundary conditions: clamped-clamped (CC), clamped-simply supported (CS) and simply supported-simply supported (SS). The fundamental frequencies of the stiffened FG cylindrical shell resting on Winkler foundation are demonstrated in Fig. $4 a$, c; and the results for Pasternak foundation are shown in Fig. 4b, d.

As we can observed, in Fig. $4 a$, c, it is clear that that fundamental frequency of the stiffened FG cylindrical shell has significant fluctuations, first decrease and then rise back with respect to $h / R$ ratio in the case of the Winkler foundation. However, as can be seen, in Fig. $4 b$, $d$, for Pasternak foundation, the results fall down versus the $h / R$ ratio.

In all cases of the $h / R$ ratios, the influences of the boundary conditions on the fundamental frequencies are larger in case of the stiffened FG cylindrical shell resting on Winkler foundation. The clamped stiffened FG cylindrical shells have the highest fundamental frequencies, whereas the simply supported stiffened FG cylindrical shells produce the smallest values.

\subsubsection{Influence of elastic foundation parameters}

Herein, the influences of elastic foundation parameters $K_{w}$ and $K_{p}$ on the fundamental frequency of the stiffened FG

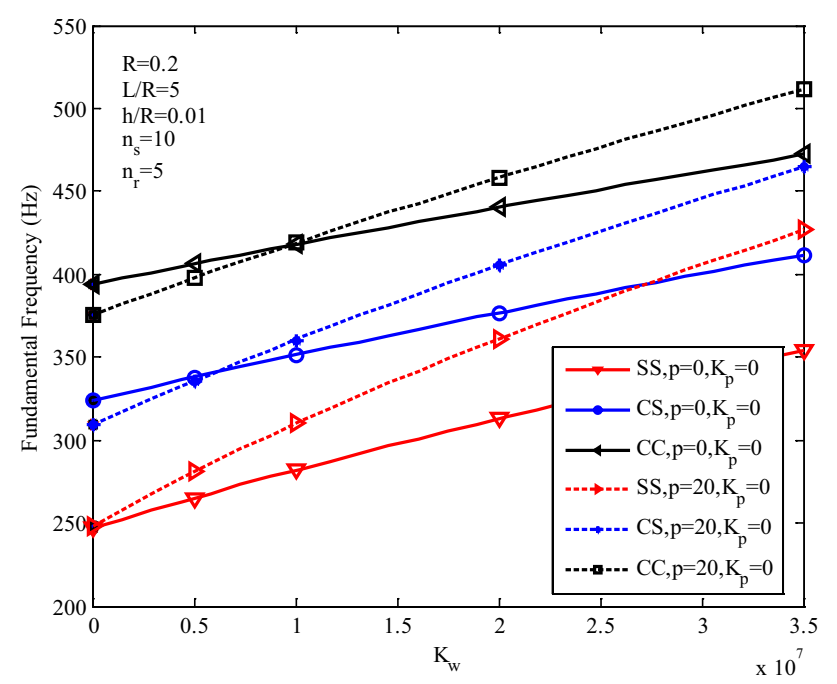

Fig. 5 The influence of elastic foundation parameter $K_{w}$ on the fundamental frequency

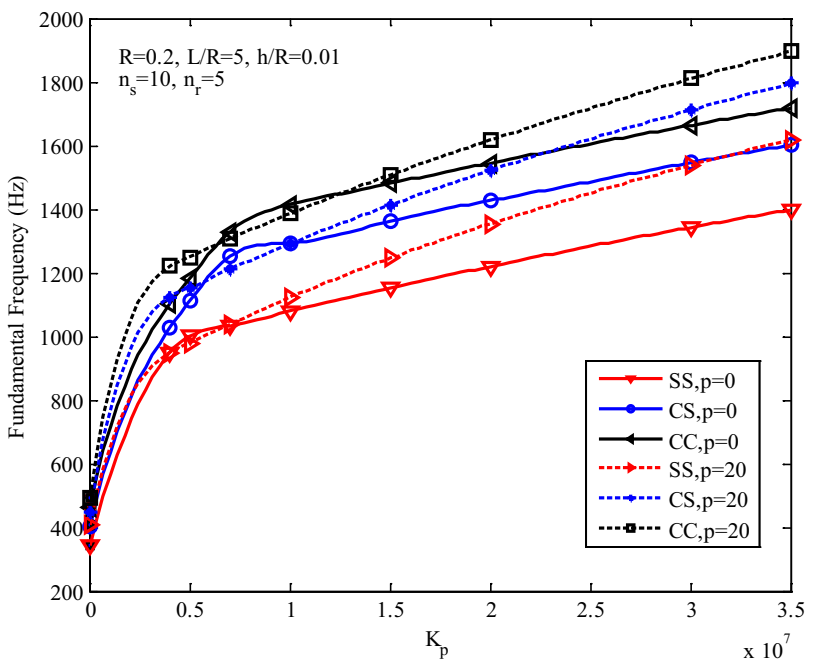

Fig. 6 The influence of elastic foundation parameter $K_{p}$ on the fundamental frequency

cylindrical shell will be presented. In particular, the effects of the elastic foundation parameter $K_{w}$ on the fundamental frequency are shown in Fig. 5, while the effects of the foundation parameter $K_{p}$ in case of $K_{w}=3.10^{7} \mathrm{~N} / \mathrm{m}^{3}$ on the results is plotted in Fig. 6 , three types of boundary conditions are also considered.

As can be seen, these two figures have some points in common when the foundation parameters increase. Firstly, the fundamental frequencies of the stiffened FG cylindrical shell structure rise up at all cases. The increment of foundation moduli lead to the enhancing of the cylindrical shell's stiffness, the higher the elastic foundation parameters are, the harder the cylindrical shell structure's stiffness are. Besides, it can be seen that most of the fundamental frequencies of the stiffened FG cylindrical shell with the volume fraction index $p=20$ increase more rapidly than those with the volume fraction index $p=0$.

In contrast, it can be seen that these two figures show some different influences stemming from two foundation parameters. The fundamental frequency of the cylindrical shell have a gradual increase versus the foundation modulus $K_{w}$, whereas the results goes up significantly at the beginning and then goes slowdown in the case of the foundation modulus $K_{p}$. Furthermore, the clamped stiffened cylindrical shells usually produce results higher than those of other boundary conditions do.

\section{Conclusions}

Based on the first-order shear deformation theory (FSDT), Lekhnitsky smeared stiffeners technique, and the Galerkin method, this study presents an analytical solution for the 
free vibration of stiffened functionally graded cylindrical shell resting on Winkler-Pasternak foundation with several boundary conditions. Some investigations relating to the influences of volume fraction index, geometric ratios, boundary conditions and elastic foundation parameters on the fundamental frequency of the stiffened FG cylindrical shell are reported. Some key points can be given:

- The fundamental frequencies of the stiffened FG cylindrical shell fall down as the ratios $L / R$ increase. The small $L / R$ ratios are sensitive on fundamental frequency of the stiffened FG cylindrical shell. The influence of the boundary conditions on the fundamental frequency of the stiffened FG cylindrical shell structure resting on Pasternak foundation is rather small as ratio $L / R>18$.

- For Winkler foundation, the fundamental frequency of the stiffened FG cylindrical shell first decreases, and then rising back with respect to $h / R$ ratio. However, for Pasternak foundation, the results fall down versus the $h / R$ ratio.
- The clamped stiffened FG cylindrical shells always get highest fundamental frequencies, whereas the simply supported stiffened FG cylindrical shells produce smallest values in all cases investigated.

- The effects of volume fraction index on the fundamental frequency of the stiffed FG cylindrical shell are more clearly as the elastic foundation parameters $K_{w}, K_{p}$ rise.

Funding This study was supported by National University of Civil Engineering (NUCE).

\section{Compliance with ethical standards}

Conflict of interest The authors declare that they have no conflict of interest.

\section{Appendix}

Differential operators of Eq. (8):

$$
\begin{aligned}
& L_{11}=\left(A_{11}+\frac{E_{s} A_{s}}{S_{s}}\right) \frac{\partial^{2}}{\partial x^{2}}+\frac{A_{66}}{R^{2}} \frac{\partial^{2}}{\partial \theta^{2}} ; \quad L_{21}=\frac{\left(A_{12}+A_{66}\right)}{R} \frac{\partial^{2}}{\partial x \partial \theta} ; L_{31}=-\frac{A_{12}}{R} \frac{\partial}{\partial x} \\
& L_{41}=\left(B_{11}+\frac{E_{s} A_{s} z_{s}}{s_{s}}\right) \frac{\partial^{2}}{\partial x^{2}}+\frac{B_{66}}{R^{2}} \frac{\partial^{2}}{\partial \theta^{2}} ; \quad L_{51}=\frac{\left(B_{12}+B_{66}\right)}{R} \frac{\partial^{2}}{\partial x \partial \theta} \\
& L_{12}=\frac{\left(A_{12}+A_{66}\right)}{R} \frac{\partial^{2}}{\partial x \partial \theta} ; \quad L_{22}=A_{66} \frac{\partial^{2}}{\partial x^{2}}+\frac{1}{R^{2}}\left(A_{22}+\frac{E_{r} A_{r}}{s_{r}}\right) \frac{\partial^{2}}{\partial \theta^{2}}-\frac{k_{s}}{R^{2}}\left(A_{44}+\frac{G_{r} A_{r}}{s_{r}}\right) \\
& L_{32}=-\frac{1}{R^{2}}\left[\left(A_{22}+\frac{E_{r} A_{r}}{s_{r}}\right)+k_{s}\left(A_{44}+\frac{G_{r} A_{r}}{s_{r}}\right)\right] \frac{\partial}{\partial \theta} ; \quad L_{42}=\frac{\left(B_{12}+B_{66}\right)}{R} \frac{\partial^{2}}{\partial x \partial \theta} \\
& L_{52}=B_{66} \frac{\partial^{2}}{\partial x^{2}}+\frac{1}{R^{2}}\left(B_{22}+\frac{E_{r} A_{r} z_{r}}{s_{r}}\right) \frac{\partial^{2}}{\partial \theta^{2}}+\frac{k_{s}}{R}\left(A_{44}+\frac{G_{r} A_{r}}{s_{r}}\right) \\
& L_{13}=\frac{A_{12}}{R} \frac{\partial}{\partial x} ; \quad L_{23}=\frac{1}{R^{2}}\left[\left(A_{22}+\frac{E_{r} A_{r}}{s_{r}}\right)+k_{s}\left(A_{44}+\frac{G_{r} A_{r}}{s_{r}}\right)\right] \frac{\partial^{2}}{\partial \theta} \\
& L_{33}=\left[k_{s}\left(A_{55}+\frac{G_{s} A_{s}}{s_{s}}\right)+K_{p}\right] \frac{\partial^{2}}{\partial x^{2}}+\left[\frac{k_{s}}{R^{2}}\left(A_{44}+\frac{G_{r} A_{r}}{s_{r}}\right)+\frac{K_{p}}{R^{2}}\right] \frac{\partial^{2}}{\partial \theta^{2}}-\frac{1}{R^{2}}\left(A_{22}+\frac{E_{r} A_{r}}{s_{r}}\right)-K_{w} \\
& L_{43}=\left[\frac{B_{12}}{R}-k_{s}\left(A_{55}+\frac{G_{s} A_{s}}{s_{s}}\right)\right] \frac{\partial}{\partial x} ; \quad L_{53}=\left[\frac{1}{R^{2}}\left(B_{22}+\frac{E_{r} A_{r} z_{r}}{s_{r}}\right)-\frac{k_{s}}{R}\left(A_{44}+\frac{G_{r} A_{r}}{s_{r}}\right)\right] \frac{\partial}{\partial \theta} \\
& L_{14}=\left(B_{11}+\frac{E_{s} A_{s} z_{s}}{s_{s}}\right) \frac{\partial^{2}}{\partial x^{2}}+\frac{B_{66}}{R^{2}} \frac{\partial^{2}}{\partial \theta^{2}} ; \quad L_{24}=\frac{\left(B_{12}+B_{66}\right)}{R} \frac{\partial^{2}}{\partial x \partial \theta} ; L_{34}=\left[k_{s}\left(A_{55}+\frac{G_{s} A_{s}}{s_{s}}\right)-\frac{B_{12}}{R}\right] \frac{\partial}{\partial x} \\
& L_{44}=\left(D_{11}+\frac{E_{s} I_{s}}{s_{s}}\right) \frac{\partial^{2}}{\partial x^{2}}-k_{s}\left(A_{55}+\frac{G_{s} A_{s}}{s_{s}}\right)+\frac{D_{66}}{R^{2}} \frac{\partial^{2}}{\partial \theta^{2}} ; \quad L_{54}=\frac{\left(D_{12}+D_{66}\right)}{R} \frac{\partial^{2}}{\partial x \partial \theta} \\
& L_{15}=\frac{\left(B_{12}+B_{66}\right)}{R} \frac{\partial^{2}}{\partial x \partial \theta} ; \quad L_{25}=B_{66} \frac{\partial^{2}}{\partial x^{2}}+\frac{1}{R^{2}}\left(B_{22}+\frac{E_{r} A_{r} z_{r}}{s_{r}}\right) \frac{\partial^{2}}{\partial \theta^{2}}+\frac{k_{s}}{R}\left(A_{44}+\frac{G_{r} A_{r}}{s_{r}}\right) \\
& L_{35}=\left[\frac{k_{s}}{R}\left(A_{44}+\frac{G_{r} A_{r}}{s_{r}}\right)-\frac{1}{R^{2}}\left(B_{22}+\frac{E_{r} A_{r} z_{r}}{s_{r}}\right)\right] \frac{\partial}{\partial \theta} ; \quad L_{45}=\frac{\left(D_{12}+D_{66}\right)}{R} \frac{\partial^{2}}{\partial x \partial \theta} \\
& L_{55}=D_{66} \frac{\partial^{2}}{\partial x^{2}}-k_{s}\left(A_{44}+\frac{G_{r} A_{r}}{s_{r}}\right)+\frac{1}{R^{2}}\left(D_{22}+\frac{E_{r} I_{r}}{s_{r}}\right) \frac{\partial^{2}}{\partial \theta^{2}}
\end{aligned}
$$




\section{References}

1. Ghayesh MH, Farokhi H, Amabili M (2014) In-plane and out-ofplane motion characteristics of microbeams with modal interactions. Compos B Eng 60:423-439

2. Ghayesh MH (2018) Functionally graded microbeams: simultaneous presence of imperfection and viscoelasticity. Int J Mech Sci 140:339-350

3. Ghayesh MH, Farokhi H, Alici G (2016) Size-dependent performance of microgyroscopes. Int J Eng Sci 100:99-111

4. Farokhi H, Ghayesh MH, Amabili M (2013) Nonlinear dynamics of a geometrically imperfect microbeam based on the modified couple stress theory. Int J Eng Sci 68:11-23

5. Gholipour A, Farokhi H, Ghayesh MH (2015) In-plane and outof-plane nonlinear size-dependent dynamics of microplates. Nonlinear Dyn 79(3):1771-1785

6. Ghayesh MH, Amabili M, Farokhi H (2013) Three-dimensional nonlinear size-dependent behaviour of Timoshenko microbeams. Int J Eng Sci 71:1-14

7. Ghayesh MH (2018) Dynamics of functionally graded viscoelastic microbeams. Int J Eng Sci 124:115-131

8. Ghayesh MH, Farokhi H (2015) Chaotic motion of a parametrically excited microbeam. Int J Eng Sci 96:34-45

9. Ghayesh $\mathrm{MH}$ (2018) Nonlinear vibration analysis of axially functionally graded shear-deformable tapered beams. Appl Math Model 59:583-596

10. Ghasemi AR, Meskini M (2019) Investigations on dynamic analysis and free vibration of FGMs rotating circular cylindrical shells. SN Appl Sci 1(4):301

11. Leissa AW (1973) Vibration of shells, vol 288. Scientific and Technical Information Office, National Aeronautics and Space Administration, Washington

12. Arnold R, Warburton $G$ (1949) Flexural vibrations of the walls of thin cylindrical shells having freely supported ends. Proc R Soc Lond A 197(1049):238-256

13. Chung $H$ (1981) Free vibration analysis of circular cylindrical shells. J Sound Vib 74(3):331-350

14. Soldatos K, Hadjigeorgiou V (1990) Three-dimensional solution of the free vibration problem of homogeneous isotropic cylindrical shells and panels. J Sound Vib 137(3):369-384

15. Loy C, Lam K, Shu C (1997) Analysis of cylindrical shells using generalized differential quadrature. Shock Vib 4(3):193-198

16. Khalili S, Davar A, Fard KM (2012) Free vibration analysis of homogeneous isotropic circular cylindrical shells based on a new three-dimensional refined higher-order theory. Int J Mech Sci 56(1):1-25

17. Spillers W (1967) A laminated thin cylindrical shell under axisymmetric static loading. Int J Mech Sci 9(12):863-871

18. Zukas JA, Vinson JR (1971) Laminated transversely isotropic cylindrical shells. J Appl Mech 38(2):400-407

19. Bert CW, Birman V (1988) Parametric instability of thick, orthotropic, circular cylindrical shells. Acta Mech 71(1-4):61-76

20. Farokhi H, Ghayesh MH (2018) Nonlinear mechanical behaviour of microshells. Int J Eng Sci 127:127-144

21. Farokhi H, Ghayesh MH (2019) Modified couple stress theory in orthogonal curvilinear coordinates. Acta Mech 230(3):851-869

22. Ghayesh $\mathrm{MH}$, Farokhi $\mathrm{H}$ (2017) Nonlinear mechanics of doubly curved shallow microshells. Int J Eng Sci 119:288-304

23. Ghayesh $\mathrm{MH}$, Farokhi H (2018) Nonlinear dynamics of doubly curved shallow microshells. Nonlinear Dyn 92(3):803-814

24. Tuan TA et al (2017) Vibration analysis of cross-ply laminated composite doubly curved shallow shell panels with stiffeners. J Sci Technol 55(3):382-392
25. Tu TM et al (2017) Optimisation of stiffeners for maximum fundamental frequency of cross-ply laminated cylindrical panels using social group optimization and smeared stiffener method. Thin-Walled Struct 120:172-179

26. Tran MT, Nguyen VL, Trinh AT (2017) Static and vibration analysis of cross-ply laminated composite doubly curved shallow shell panels with stiffeners resting on Winkler-Pasternak elastic foundations. Int J Adv Struct Eng 9(2):153-164

27. Chi S-H, Chung Y-L (2006) Mechanical behavior of functionally graded material plates under transverse load-part I: analysis. Int J Solids Struct 43(13):3657-3674

28. Chi S-H, Chung Y-L (2006) Mechanical behavior of functionally graded material plates under transverse load-part II: numerical results. Int J Solids Struct 43(13):3675-3691

29. Hosseini-Hashemi $S$ et al (2010) Free vibration of functionally graded rectangular plates using first-order shear deformation plate theory. Appl Math Model 34(5):1276-1291

30. Reddy JN (2004) Mechanics of laminated composite plates and shells: theory and analysis. CRC Press, Boca Raton

31. Mechab I et al (2010) A two variable refined plate theory for the bending analysis of functionally graded plates. Acta Mech Sin 26(6):941-949

32. Talha M, Singh B (2010) Static response and free vibration analysis of FGM plates using higher order shear deformation theory. Appl Math Model 34(12):3991-4011

33. Thai H-T, Kim S-E (2013) A simple higher-order shear deformation theory for bending and free vibration analysis of functionally graded plates. Compos Struct 96:165-173

34. Vu T-V et al (2017) A simple FSDT-based meshfree method for analysis of functionally graded plates. Eng Anal Bound Elem 79:1-12

35. Yu TT et al (2015) A simple FSDT-based isogeometric analysis for geometrically nonlinear analysis of functionally graded plates. Finite Elem Anal Des 96:1-10

36. Yu T et al (2016) NURBS-based isogeometric analysis of buckling and free vibration problems for laminated composites plates with complicated cutouts using a new simple FSDT theory and level set method. Thin-Walled Struct 101:141-156

37. Yin S et al (2014) Isogeometric locking-free plate element: a simple first order shear deformation theory for functionally graded plates. Compos Struct 118:121-138

38. Hoppmann WH (1958) Some characteristics of the flexural vibrations of orthogonally stiffened cylindrical shells. J Acoust Soc Am 30(1):77-82

39. Egle DM, Sewall J (1968) An analysis of free vibration of orthogonally stiffened cylindrical shells with stiffeners treated as discrete elements. AIAA J 6(3):518-526

40. Rinehart S, Wang J (1972) Vibration of simply supported cylindrical shells with longitudinal stiffeners. J Sound Vib 24(2):151-163

41. Mustafa B, Ali R (1989) An energy method for free vibration analysis of stiffened circular cylindrical shells. Comput Struct 32(2):355-363

42. Kim Y-W (2015) Free vibration analysis of FGM cylindrical shell partially resting on Pasternak elastic foundation with an oblique edge. Compos B Eng 70:263-276

43. Shah AG et al (2010) Vibrations of functionally graded cylindrical shells based on elastic foundations. Acta Mech 211(3-4):293-307

44. Sheng G, Wang X (2007) Effects of thermal loading on the buckling and vibration of ring-stiffened functionally graded shell. $J$ Therm Stresses 30(12):1249-1267

45. Naeem MN et al (2012) Vibration characteristics of ring-stiffened functionally graded circular cylindrical shells. ISRN Mech Eng 2012 
46. Tran MT, Nguyen VL (2016) Vibration analysis of rotating functionally graded cylindrical shells with orthogonal stiffeners. Latin Am J Solids Struct 13(15):2652-2669

47. Talebitooti M, Daneshjou K, Talebitooti R (2013) Vibration and critical speed of orthogonally stiffened rotating FG cylindrical shell under thermo-mechanical loads using differential quadrature method. J Therm Stresses 36(2):160-188

48. Tran MT, Nguyen VL (2016) Design, manufacturing and applications of composites. In: Proceedings of the eleventh joint Canada-Japan workshop on composites, Ho Chi Minh, Vietnam, 8-10 Aug 2016

49. Loi NV, Dinh TB, Binh CT (2018) Free vibration analysis of functionally graded cylindrical shell with stiffeners. J Sci Technol Civ Eng 12(6):20-28

50. Ozdemir M et al (2018) Numerical buckling analysis for flat and cylindrical shells including through crack employing effective reproducing kernel meshfree modeling. Eng Anal Bound Elem 97:55-66

51. Yoshida K et al (2017) Meshfree flat-shell formulation for evaluating linear buckling loads and mode shapes of structural plates. J Mar Sci Technol 22(3):501-512

52. Sadamoto $S$ et al (2017) Buckling analysis of stiffened plate structures by an improved meshfree flat shell formulation. ThinWalled Struct 117:303-313

53. Ozdemir M et al (2018) Application of 6-DOFs meshfree modeling to linear buckling analysis of stiffened plates with curvilinear surfaces. Acta Mech 229(12):4995-5012

54. Talebitooti M, Ghasemi M, Hosseini S (2017) Vibration analysis of functionally graded cylindrical shells with different boundary conditions subjected to thermal loads. J Comput Appl Res Mech Eng (JCARME) 6(2):103-114

55. Lin H, Cao D, Shao C (2018) An admissible function for vibration and flutter studies of FG cylindrical shells with arbitrary edge conditions using characteristic orthogonal polynomials. Compos Struct 185:748-763
56. Wang $Q$ et al (2017) Benchmark solution for free vibration of thick open cylindrical shells on Pasternak foundation with general boundary conditions. Meccanica 52(1-2):457-482

57. Wang Y, Wu D (2017) Free vibration of functionally graded porous cylindrical shell using a sinusoidal shear deformation theory. Aerosp Sci Technol 66:83-91

58. Pradhan $\mathrm{S}$ et al (2000) Vibration characteristics of functionally graded cylindrical shells under various boundary conditions. Appl Acoust 61(1):111-129

59. Lam K, Qian W (2000) Free vibration of symmetric angle-ply thick laminated composite cylindrical shells. Compos B Eng 31(4):345-354

60. Reddy JN (2006) Theory and analysis of elastic plates and shells. CRC Press, Boca Raton

61. Bich DH, Van Dung D, Nam VH (2012) Nonlinear dynamical analysis of eccentrically stiffened functionally graded cylindrical panels. Compos Struct 94(8):2465-2473

62. Najafizadeh M, Hasani A, Khazaeinejad P (2009) Mechanical stability of functionally graded stiffened cylindrical shells. Appl Math Model 33(2):1151-1157

63. Van Dung D, Nga NT (2013) Nonlinear buckling and post-buckling of eccentrically stiffened functionally graded cylindrical shells surrounded by an elastic medium based on the first order shear deformation theory. Vietnam J Mech 35(4):285-298

64. Li H, Lam K-Y, Ng T-Y (2005) Rotating shell dynamics, vol 50. Elsevier, Amsterdam

65. Lam K, Loy C (1998) Influence of boundary conditions for a thin laminated rotating cylindrical shell. Compos Struct 41(3-4):215-228

Publisher's Note Springer Nature remains neutral with regard to jurisdictional claims in published maps and institutional affiliations. 